\title{
O AVANÇO DA PECUÁRIA BOVINA SOBRE AS ÁREAS DE CULTIVO DE ALIMENTOS BÁSICOS E SUAS IMPLICAÇÕES NO MUNICIPIO DE LAGOA DO OURO - PE
}

\author{
Kate Mila Santana Machado ${ }^{1}$
}

José Laudienio Peixoto ${ }^{2}$

Maria Betânia Moreira Amador ${ }^{3}$

RESUMO: O presente trabalho visa o estudo da atividade agropecuária no município de Lagoa do Ouro, localizado na Mesorregião do Agreste de Pernambuco, Microrregião de Garanhuns. A área de análise para essa pesquisa, voltada para a compreensão de problemas de interesse coletivo no âmbito local, e que tem como foco, o desenvolvimento do setor agropecuário desse município, o qual passa por modificações de caráter social e econômico. Nos brejos altos do Agreste, onde está localizado o referido município, desenvolveram-se a princípio, atividades agrícolas destinadas à alimentação da população local. Atualmente é realizada a agricultura de subsistência, sendo utilizado nessa atividade práticas inadequadas, que conciliadas com questões climáticas e falta de investimentos político-administrativos, proporciona uma pequena produção, considerada insuficiente para o sustento do agricultor e sua família. Sem condições de se manter da sua produção agrícola, estes proprietários são obrigados a buscar alternativas para que possam atender as necessidades da sua família. Essas alternativas tornaram-se uma fonte de renda buscada fora da sua propriedade, principalmente pela substituição da atividade agrícola pela pecuária bovina, atividade esta que neste município representa, na atualidade, a principal atividade do setor agropecuário, pois é realizada em cerca de $90 \%$

\footnotetext{
${ }^{1}$ Geógrafa; Pós-graduanda em Geografia. Universidade de Pernambuco - Campus Garanhuns. E-mail: katemila_10@hotmail.com

${ }^{2}$ Geógrafo. E-mail: dienio_44@hotmail.com

3 Orientadora: $\operatorname{Prof}^{\mathrm{a}} \operatorname{Dr}^{\mathrm{a}}$ da Universidade de Pernambuco - Campus Garanhuns. E-mai: betaniaamador@yahoo.com.br
} 
das terras produtivas do município. No entanto, é uma atividade que além de concentrar grandes extensões de terras em posse de poucos, também não oferece empregos em quantidade suficiente para atender a mão-de-obra ociosa local, gerando ao longo do tempo uma desestabilização de ordem econômica.

PALAVRAS-CHAVES: Agricultura, Pecuária, Lagoa do Ouro/PE.

\section{Introdução}

O referido estudo evidencia e analisa a atividade pecuária e seu avanço sobre as áreas agrícolas no município de Lagoa do Ouro/PE, como alternativa encontrada pelo homem do campo para garantir sua sobrevivência na terra, em detrimento à baixa produtividade apresentada pela agricultura do município, questões essas abordadas no respectivo trabalho.

A pecuária bovina foi a causa do povoamento do Agreste de Pernambuco, e é até hoje a atividade de maior importância para essa região, seja por questões culturais, físicas, climáticas, econômicas e, até mesmo políticas. Trata-se de atividade muito rentável, sobretudo, para os seus produtores, possibilitando assim, uma vasta concentração de terras nas mãos de poucos, dando origem a latifúndios destinados à pecuária bovina; outro problema da pecuária é que não gera emprego na mesma proporção que cresce, dando origem a problemas sócio-econômicos, como o desemprego e a migração campo-cidade.

No município de Lagoa do Ouro, houve um acentuado crescimento da atividade pecuária nos últimos anos, sobretudo a leiteira, como alternativa encontrada pelos produtores para a baixa produtividade agrícola que o município apresenta. A pecuária bovina vem se estabilizando cada vez mais, pelas inúmeras vantagens que essa atividade oferece para os seus produtores como por exemplo: não é tão vulnerável às mudanças climáticas como a agricultura, e gera lucro para o ano todo, não necessita de muita mãode-obra como ocorre na agricultura. 
No âmbito político, a pecuária do Agreste de Pernambuco vem sofrendo influências positivas, como, políticas públicas de incentivo a produção leiteira no estado, cita-se a iniciativa de Pernambuco em parceria com o Governo Federal, em associação com a Secretaria de Produção Rural e Reforma Agrária (SPRRA) e a Companhia de Abastecimento e de Armazéns Gerais do Estado de Pernambuco (CEAGEPE), com o lançamento do Programa Leite a famílias carentes.

Más, no município em estudo, nem todos puderam substituir totalmente a agricultura em declínio pelas vantagens que a pecuária bovina proporciona, a pecuária é atividade que necessita de grandes extensões de terra, ou seja, cada boi irá necessitar de um hectare para pastar, e a grande maioria dos produtores do município possui minifúndios, com menos de 10 hectares, sem poder substituir definitivamente uma atividade pela outra. Logo, procuram conciliar em sua pequena propriedade pecuária e a pequena agricultura de subsistência, mesmo assim, no município em estudo, a pecuária só está ascendendo. Acredita-se que a razão seja porque trata-se de atividade praticada em todo município, apresenta vantagens em relação a agricultura, e porque, há pecuaristas no município que dispõe de melhores condições para a evolução da pecuária, usufruindo de vários hectares de terra para o desenvolvimento da bovinocultura. No entanto, esses pecuaristas são minoria no total dos produtores do município, e como tal, não proporciona um bom desenvolvimento à economia local, porque a pecuária é atividade essencialmente capitalista, em que a maior parte dos lucros fica para 0 proprietário lembrando, ainda, que a pecuária não emprega da mesma forma que evolui, gerando uma concentração de terras nas mãos de poucos, fazendo com que o lucro fique restrito na posse de uma minoria.

Por outro lado, a agricultura do município de Lagoa do Ouro também passa por transformações. Nos últimos anos essa atividade está declinando cada vez mais, reflexo de todo um processo excludente que a agricultura de subsistência do município em estudo vem vivenciando; fatores climáticos e edáficos sempre contribuíram para um acentuado declínio da agricultura local, práticas arcaicas no manejo do solo, como, queimadas e produtos químicos, utilizados sem o devido conhecimento para a limpa do mesmo ainda é muito utilizado segundo os agricultores locais; o baixo nível de 
escolaridade ainda faz parte da realidade local, tudo isso atrelado à falta de investimentos por parte do governo local e estadual para a agricultura de subsistência do município. Todo esse atraso na agricultura do município em estudo resulta em um baixo número de áreas destinadas à agricultura: 1.285 estabelecimentos com 2.213 hectares, contra 1.187 estabelecimentos com 13.614 hectares destinados à pecuária, esses dados confirmam a difícil situação para o agricultor manter-se nesse cenário de ascendente progresso pecuário na maioria das vezes excludente; Fonte IBGE (Instituto Brasileiro de Geografia e Estatística).

No decorrer deste trabalho, pode-se observar que a expansão da pecuária bovina, mesmo com todas as vantagens que ela proporciona, trouxe problemas para o município, porque a mesma é atividade muito concentradora de riqueza nas mãos de poucos, ficando uma maioria tentando manter-se alternando entre a agricultura de subsistência e a criação de alguns poucos animais, sem assistência governamental e a mercê de todas as condições desfavoráveis possíveis. É nesse contexto que insere-se o presente trabalho acadêmico, buscando-se analisar as mudanças ocorridas no cenário agropecuário do município de Lagoa do Ouro e suas implicações, objetivando-se uma melhor compreensão dos fenômenos ocorridos e como resultado desse avanço observa-se que hoje a atividade agropecuária vem mudando significativamente a realidade desse município do agreste pernambucano, atrelado a agricultura de subsistência que está em declínio.

O estudo em questão está dividido nos seguintes tópicos: A colonização de Pernambuco e do Agreste de Pernambuco, A Agricultura de Subsistência e a Expansão da Pecuária no Município de Lagoa do Ouro, dentre outros subtópicos.

\section{A Colonização de Pernambuco}

A colonização portuguesa no território brasileiro deu-se por volta do sec. XVI, sendo a costa nordestina, dentre a grande extensão litorânea brasileira, a primeira a ser 
explorada. Dentro do contexto histórico da colonização do Brasil, começara incansáveis lutas para desbravar esse território. Os posteriores donatários que aí iam surgindo, tinham um grande trabalho, acompanhados de amigos, escravizando índios, para assim adentrar e desmatar áreas de mata consideradas as mais propícias para a cultura da cana-deaçúcar; após adentrar e desmatar a mata ia estalando engenhos, as casas-grandes, as senzalas, plantando os canaviais e as lavouras de mantimentos e para que essa atividade se desenvolvesse a contento, os sesmeiros necessitavam ter animais - bois e cavalos importados da Europa - e escravos vindos da África.

Nas áreas mais interiorizadas, afastadas das regiões das matas, onde as condições climáticas e edáficas não apresentavam condições favoráveis para a cultura da cana-de-açúcar, como nos tabuleiros litorâneos ou nas caatingas localizadas a oeste e ao norte da Borborema, os proprietários organizaram currais e criaram o gado necessário para suprir a alimentação e os animais de trabalho para atender as necessidades da área açucareira, primeiramente de Olinda/PE .

A pecuária crescia de importância econômica a medida que caminhava para o sul, uma vez que era a atividade exclusiva na zona do São Francisco e no território alagoano; assim, no Brasil colonial e imperial, em função dessa atividade econômica, estabeleceuse verdadeira dinastia de criadores de gado expandindo-se para áreas sertanejas, tornando-se famosos e poderosos latifundiários. Nesse contexto a agricultura, ou melhor, a pequena lavoura no Nordeste, já de então, começa sem grandes propósitos, só para manter a província, e até mesmo, algumas vezes, com insuficiente produção.

Contudo, a pecuária se solidificou como uma atividade econômica que ascende cada vez mais no Brasil colonial, sendo os bois utilizados em grande escala na cultura da cana, pois, a necessidade desses animais era enorme, uma vez que toda a cultura da cana, ora era manual, ora era mecânica, precisando de grande número de animais para tração. O gado foi sempre servo da cana, ocupando áreas cada vez mais distantes do litoral, se não fosse a pecuária os tabuleiros haviam se tornado verdadeiro vazio demográfico, sendo o gado fator predominante para o desbravamento de imensas áreas do Agreste e Sertão. 


\section{A Introdução da Pecuária Bovina no Agreste de Pernambuco}

A pecuária bovina foi desde o início uma atividade de suporte para produção da cana, sendo o gado largamente utilizado no desenvolvimento da atividade açucareira com animais de grande porte e bastantes numerosos. Aqueles animais que não estavam sendo utilizados na atividade agrícola da cana iam sendo levados cada vez mais distantes da Zona da Mata, geralmente recuados a amplos tabuleiros cada vez mais interiorizados, sobretudo nas áreas drenadas pelo São Francisco e pelo Cururipe, dando origem a uma pecuária extensiva.

A criação de gado inicia-se como uma atividade econômica independente para aqueles que não conseguiram se estabelecer na atividade canavieira.

O Agreste de Pernambuco, localizado quase inteiramente sobre a Borborema, encontrava-se próximo do litoral e proporcionava condições muito favoráveis ao desenvolvimento da pecuária extensiva. Porém, foi tardiamente povoado, e só a porção baixa situada ao sopé da serra é que foi ocupada, sendo contornada ao Sul, por criadores de gado quando subia o São Francisco, ao Norte, quando alcançavam e subiam os vales do Açu e do Apodi e ao Oeste, quando os criadores baianos transpuseram o rio São Francisco e subiam seus afluentes da margem esquerda - O Moxotó e o Pajeú, sendo o Ipanema, a vía de penetração para o Agreste. No entanto, só após a guerra holandesa é que o Agreste seria conquistado, e economicamente integrado ao Nordeste. Andrade (1998, p.137), por sua vez, endossa essa colocação ao ressaltar:

A criação de gado foi desde os primeiros tempos uma atividade econômica subsidiária da cana-de-açúcar. Os engenhos eram quase sempre movidos a tração animal e, tanto o transporte da cana, dos partidos para a fábrica, como o transporte do açúcar, das fábricas para os portos de embarque, estavam sempre a exigir grande número de bois e de cavalos. A guerra holandesa e o medo de perder seus animais, requisitados pelos invasores, fizeram com que criadores alagoanos e sergipanos subissem o Rio São Francisco em demanda do sertão.

Logo, admite-se que foi a expansão pecuária a causa do desbravamento do Agreste, atividade sempre sedenta por novas áreas. Essa atividade pecuária foi expandindo-se mais e mais no Agreste e fazendo com que seus habitantes nativos, os 
índios, recuassem cada vez mais, se localizando em trechos de serra e brejos altos, menos acessíveis e cobiçados pelos criadores de gado. Assim o Agreste disponibilizava extensões aplainadas, propícias à criação de gado, e tinha também o capim de cheiro e o mimoso, favoráveis ao desenvolvimento da pecuária bovina; a agricultura de subsistência ficava destinada aos brejos, áreas úmidas e que dispunham de água nos leitos dos rios durante a estação chuvosa, formavam assim, uma economia própria, que se autoabastecia, além das dificuldades de acessos por causa do relevo acidentado, só o gado é que se autotransportava para as cidades onde se localizavam os engenhos.

Ainda hoje podemos observar como, no Agreste e no Sertão, a criação de gado é a atividade econômica mais ligada ao latifúndio, pois os grandes proprietários são sempre, principalmente, pecuaristas, e só subsidiariamente, agricultores. Esta regra só é quebrada nos brejos, onde as condições climáticas são desfavoráveis à criação de bovinos e onde a propriedade está quase sempre muito dividida. (Andrade, 1998, p.145).

Dessa forma, observa-se que a atividade da pecuária além de exercer forte influência econômica no Agreste, molda também, os costumes da região.

\section{A Agricultura no Desenvolvimento do Agreste}

Como exposto anteriormente, o Agreste possuía uma economia agrícola interna pelo fato do seu difícil acesso, raramente importando e exportando produtos agrícolas para outras áreas, somente o gado se autotransportava para a região da Mata. Dessa forma, para prover sua própria alimentação à população do Agreste desenvolvia a agricultura de subsistência. Nesse caminhar e também pela necessidade de novas áreas agrícolas, derrubavam-se trechos de matas existentes nos brejos, fazendo roçados onde os agricultores cultivavam alimentos básicos como feijão, milho e a mandioca. Foram assim que os brejos de altitude passaram a ser povoados, abastecendo o Agreste de gêneros alimentícios; Exemplifica-se com Garanhuns/PE, cidade que está localizada em uma zona elevada e úmida que à época já desenvolvia uma importante agricultura de subsistência. 
Em geral a população agrestina era pobre, limitando-se a cultivar o algodão, cultura que em alguns períodos mostrava-se em alta, enquanto as lavouras davam sempre lucros reduzidos, e o gado, por sua vez, era destinado ao abastecimento interno e não dava grandes despesas, nem também grandes lucros.

No entanto, o Agreste passou por várias transformações nas relações agropecuárias; com o cultivo do algodão a partir de 1750 que começou a ter importância e a pesar na economia do Nordeste, ao plantio do café, produto que transformaria as paisagens agrestinas; passando de pecuarista no séc. XVIII, para essencialmente policultor, no séc. XIX e XX, tornando-se uma região importante na exportação de alimentos básicos para o Nordeste, isso se deu principalmente, devido a uma melhoria na assistência técnica, no aumento da densidade demográfica e na melhoria das estradas facilitando assim, o escoamento dos alimentos para as capitais, como define Andrade.

Nesse contexto, a pecuária perde espaço, em relação às extensões de terra que antes eram destinadas a essa atividade, para dar lugar às áreas agrícolas. Entretanto, a pecuária não foi prejudicada, pelo contrário, até cresceu, porque essa atividade deixava de ser extensiva para ser intensiva, investindo mais na qualidade e em assistência técnica, tornando-se uma atividade altamente compensadora para o Agreste.

\section{A Agricultura no Município de Lagoa do Ouro - PE}

A ocupação do referido município deu-se tardiamente pois a pecuária, atividade produtiva que favoreceu o povoamento do Agreste e do Sertão, encontrava nessas áreas grandes obstáculos, seja na dificuldade de acesso como também no clima, por vezes muito frio para a criação bovina.

Só quando as áreas ao redor dos brejos já estavam quase totalmente ocupadas e com uma população bastante numerosa é que os brejos úmidos foram sendo povoados pelo excedente populacional dessas regiões, como ressalta Andrade (1998, p.141): 
Nos meados do século XVII, quando a população agrestina já crescera bastante e a pecuária extensiva não era capaz de absorver a mão-de-obra ai existente, os índios refugiados nos brejos de altitude foram sendo aldeados e as secas fazendo com que os habitantes da caatinga se abrigassem nos brejos úmidos, ambientando os mesmos á coleta dos produtos florestais e à agricultura; foi ai que os brejos de altitudes passaram a ser mais densamente povoados. Aí iriam grupos humanos que se dedicavam á agricultura de mantimentos e á cultura da cana-deaçúcar, que era transformada por engenhos em rapadura e aguardente, dando origem a sítios e até pequenas vilas.

Esses primeiros habitantes foram desenvolvendo pequenos roçados, cultivados pelas próprias famílias, destinados basicamente à sua própria alimentação. Atualmente o município de Lagoa do Ouro, ainda contando com uma população predominantemente rural, onde cerca de $54 \%$ da sua população ainda reside no campo e realiza uma agricultura praticada em sua maioria em pequenas propriedades, nos chamados minifúndios, com área inferior a 10 hectares, faixa essa que representa cerca de $90 \%$ dos imóveis do município, tendo como modo de produção a agricultura familiar. Nesse contexto Tinoco (2008, p.2), define segundo Gonsalves e Souza (2005) da seguinte forma a propriedade familiar:

Na legislação brasileira a definição de Propriedade Familiar consta no inciso II do artigo 4ํㅡㄹ do Estatuto da Terra. Pela lei $n^{\circ} 4.504$ de 30/ de novembro/1964 com a seguinte redação: Propriedade Familiar como sendo o imóvel que direta e pessoalmente explorada pelo agricultor e sua família, Ihe absorva toda a força de trabalho, garantindo-Ihe a subsistência e o progresso social e econômico, com área máxima fixada para cada região e tipo de exploração e eventualmente trabalhada com ajuda de terceiros.

Em geral essa agricultura praticada nas pequenas propriedades familiares no município de Lagoa do Ouro - PE é baseada no cultivo de produtos básicos, tendo como principais culturas o feijão, o milho, a mandioca, a batata-doce, a banana, a melancia e o tomate.

Considerando-se a grande quantidade de propriedades, que no município chega a 1.700 imóveis com menos de 10 ha, ressaltando-se a grande divisão da terra, a produção agrícola no município de Lagoa do Ouro mostra-se insuficiente, tendo uma renda média de cerca de $R \$ 500,00$ por hectare/ano (IBGE, 2006), mostrando-se incapaz de suprir as necessidades básicas das famílias dos imóveis rurais: alimentação, vestuário e demais 
gastos pessoais, como também, a manutenção da propriedade. Dessa forma, sendo necessário para os que ainda persistem em viver em sua propriedade, outra fonte de renda que venha a suprir a da produção agrícola. Segundo os agricultores entrevistados, essa renda extra trata-se de aposentadorias rurais, quando há aposentado no domicilio, e outros benefícios sociais governamentais. Não havendo estes benefícios, se torna necessário buscar fora do estabelecimento familiar outra fonte de renda que complemente a produção agrícola.

No entanto, as fontes de trabalho necessárias à suplementação da renda das famílias residentes nos imóveis rurais no município são muito escassas, limitadas a pequenos serviços remunerados em outras propriedades, ou com um pouco de sorte, algum membro da família consegue um trabalho na prefeitura local ou em pequenos comércios, únicas fontes de emprego no município.

Outra alternativa encontrada pelos agricultores do município de Lagoa do Ouro, na busca de condições para permanecer no meio rural, foi a troca de atividade produtiva, ao invés de trabalhar em sua propriedade com produtos agrícolas alimentares, uma boa parte desses produtores passou a exercer, ou a dividir sua área com a atividade da pecuária bovina, sobretudo, a bovinocultura leiteira.

Aliás, em relação à pecuária, vem se caracterizando a evolução da bovinocultura nas áreas de exceção. Esse fato encontra sua causa na baixa produtividade que os pequenos produtores estão enfrentando, em função da utilização inadequada que vem dando as suas culturas vegetais, e a pouca quantidade de terra que possuem. (LINS, 1989, p. 308)

No entanto, essa alternativa que os proprietários rurais encontraram para obter melhores condições de permanência no campo, não está acessível a todos, pois, é uma atividade que necessita de uma área de produção maior, cerca de um hectare por animal, inviabilizando essa opção aos pequenos proprietários, sobretudo a maior parte daquelas com área inferior a 10 hectares, que no município representa a maioria dos imóveis rurais.

O município de Lagoa do Ouro tem, 1.748 minifúndios, correspondendo a apenas 19\% do total da área produtiva do município, tendo uma média de 2 hectares por propriedade (IBGE, 2006). Na sua maioria não oferece condições que viabilize uma criação bovina que seja capaz de gerar uma renda suficiente para manter o imóvel familia, 
o que deixa a população residente nessas propriedades, sem outra opção de fonte de renda, ou seja, em condição insustentável de permanecer no campo.

\section{Características da Aividade Agrícola no Município de Lagoa do Ouro/PE}

A baixa produtividade que a agricultura proporciona no município de Lagoa do Ouro/PE está associada a uma série de fatores, sejam eles a utilização de técnicas inadequadas ao manejo do solo e das culturas, condições climáticas por vezes desfavoráveis, como também a falta de investimentos públicos no setor, tanto em linha de crédito, como em assistência técnica.

A utilização de técnicas inadequadas no manejo da terra como, o desmatamento em áreas próximas a riachos, e a queimada da vegetação para limpar o terreno, segundo relato dos próprios agricultores visitados, ainda são práticas comumente utilizadas por eles no município, tendo como consequência, graves problemas tais como, a erosão e perda da fertilidade da terra devido à queima da meteria orgânica e dos nutrientes do solo, provocando a perda da produtividade do imóvel rural.

Além do mau desempenho da agricultura por motivos da má utilização de técnicas no manejo do solo, outro fator que preocupa o agricultor é o fator climático, pois estando o município de Lagoa do Ouro localizado sobre o Planalto da Borborema, numa área de transição entre a Mata úmida e o Sertão semiárido, apresenta uma inconstância climática, apresentando, por vezes, anos com chuvas escassas, consideradas insuficientes para um bom desenvolvimento das lavouras, já em outros pode apresentar chuvas excessivas e temperaturas muito baixas devido à altitude da região o que, da mesma forma, prejudica o desempenho da atividade agrícola ocasionando perdas consideráveis.

Não bastando todas essas dificuldades, o pequeno agricultor no município de Lagoa do Ouro tem ainda que enfrentar a falta de investimento público para o setor agrícola. 
No que se refere a investimentos públicos nesse setor há décadas relegada a segundo plano e até mesmo esquecida pelo Estado, à agricultura familiar e a sua base fundiária - a pequena propriedade - têm sobrevivido em meio à competição de condições e recursos orientados para favorecer a grande produção e a grande propriedade - setores privilegiados no processo de modernização da agricultura brasileira. (CARNEIRO, 1997, p.16).

Os investimentos públicos na agricultura do município de Lagoa do Ouro, segundo dados obtidos juntos aos agricultores visitados (2009), limitam-se a pequenos auxílios da prefeitura como, fornecimento de tratores para aragem da terra e para o beneficiamento e transporte da produção, benefícios do PRONAF (Programa Nacional para a Agricultura Familiar), com doação de sementes selecionadas e o Segura Safra, benefício governamental que tem como base amenizar o efeito cíclico da seca no semiárido, e com o objetivo de oferecer uma renda mínima aos agricultores de base familiar, que porventura venham a ter prejuízos de $50 \%$ ou mais de suas lavouras prejudicadas pela estiagem, como também empréstimos em condições especiais junto ao Banco do Nordeste, sendo estes instrumentos considerados paliativos e ineficazes em termos de incentivo ao desenvolvimento da produção rural no município de Lagoa do Ouro - PE.

\section{A Pecuária Bovina no Município de Lagoa de Ouro / PE}

A economia de Lagoa do Ouro é constituída pelo comércio, pecuária de leite, e as lavouras alimentares, como mandioca, milho, feijão e frutas. Nesse contexto a ordem econômica desses produtos possui configuração das mais variadas possíveis, com predominância para a pecuária leiteira nos últimos anos.

O Agreste teve, ao longo do tempo, sucessivas atividades econômicas em destaque como a pecuária extensiva até o século XVIII; a agricultura comercial com base nos ciclos do algodão e do café nos séculos XIX e XX; neste último voltou a ser predominantemente pecuário, com ênfase na década de setenta, então como atividade econômica propriamente rentável através da criação semiintensiva, especializada na produção de leite e de carne (ANDRADE, 1998, p. 128). 
A pecuária, além de ser favorecida pelos inúmeros projetos econômicos voltados para essa atividade no Agreste, teve outros fatores que contribuíram para o desenvolvimento pecuário, além do acentuado declínio agrícola, desestabilizando as atividades da agricultura, que eram tão característicos do município em estudo, houve também o fator, políticas publicas de incentivo à produção leiteira, como descreve Monteiro (2007, p. 666):

\begin{abstract}
Pernambuco em parceria com o Governo Federal, em associação com a Secretaria de Produção Rural e Reforma Agrária (SPRRA) e a Companhia de Abastecimento e de Armazéns Gerais do Estado de Pernambuco (CEAGEPE), lançou o Programa Leite a famílias carentes, especialmente crianças, de Pernambuco, com o principal objetivo de fornecer leite a gestantes e lactantes.
\end{abstract}

A pecuária no município de Lagoa do Ouro, também está associada ao desenvolvimento das vantagens econômicas que essa atividade dá aos seus proprietários como, por exemplo: não necessita de muita mão-de-obra para desenvolver-se, possibilita ao proprietário de terras aproveitarem por inteiro suas propriedades, até mesmo latifúndios. Também se verifica que essa atividade não envolve grandes despesas se comparadas à atividade agrícola, salienta-se ainda que a pecuária de leite e de corte é atividade econômica de grande influência no Agreste pernambucano; ressalta-se que no município em estudo, desenvolve-se principalmente a pecuária leiteira. "Dados recentes revelam que nos últimos dois anos a produção leiteira da região agreste cresceu $23 \%$, representando $73 \%$ da produção leiteira do Estado de Pernambuco" (CONSELHO NACIONAL E ABASTECIMENTO, 2004; FIGUEIROA, 2006 citado por Amador (2008, p.12).

Mas essa pecuarização, trouxe alguns problemas para o município de Lagoa do Ouro, problemas de natureza social e econômica, uma vez que, se trata de atividade que necessita de grandes extensões de terra, gerando uma concentração desse recurso na mão de poucos, constituindo-se numa atividade extremamente capitalista no meio rural. Entre outras coisas, observa-se que vêm expulsando de suas pequenas propriedades os agricultores, que sem condições de sobrevivência no meio rural, migram para as cidades próximas ou para os grandes centros do país, dando origem ou sequência ao êxodo rural, gerando problemas para o município em análise visto que os desempregados da 
agricultura são, na grande maioria, pessoas analfabetas que não vão ser absorvidas no mercado de trabalho tão facilmente.

\section{Estrutura Fundiária e Utilização da Terra}

No município de Lagoa do Ouro/PE, como acontece em todo o Nordeste, a terra é mal dividida. Do total de 16.815 hectares, tem-se 2.082 proprietários no município de Lagoa do Ouro. Enquanto 3.192 hectares, que compõem a faixa de imóveis com menos de 10 hectares, está dividida entre os 1.748 pequenos proprietários locais. E, 5.473 hectares que compreende os imóveis acima de cem hectares, estão em posse de apenas 18 proprietários (IBGE, 2006).

Essa má distribuição agrava mais ainda as condições sócias e econômicas locais, pois a utilização dada para as propriedades impossibilita o aproveitamento da mão-deobra excedente do município. Tanto nas pequenas propriedades, onde é desenvolvida a agricultura de subsistência trabalhada pela própria família, e que só eventualmente absorve força de trabalho de terceiros, como nas propriedades maiores onde se desenvolve a pecuária extensiva, o aproveitamento da força de trabalho é mínimo.

\section{Conclusão}

O município de Lagoa do Ouro PE apresenta uma economia com base no setor agropecuário, e tem ainda uma população predominantemente rural, e vem enfrentando nos últimos anos consideráveis mudanças neste setor, caracterizado pelo enfraquecimento da atividade agrícola, que sem condições de se desenvolver, devido a fatores naturais como também, pela falta de investimentos, vem ao longo dos anos perdendo espaço para a atividade da pecuária bovina, em especial a leiteira. 
Ao analisar-se os dados obtidos no presente trabalho, pode-se ressaltar que a atividade agrícola é exercida com maior intensidade nas pequenas propriedades, que representam cerca de $90 \%$ dos estabelecimentos rurais do município, agricultura essa que proporciona pouca rentabilidade, insuficiente para o sustento da família e a manutenção da propriedade familiar. Constatou-se que os pequenos agricultores conseguem permanecer nas suas propriedades desde que disponha de outra fonte de renda que supra a da produção agrícola.

No entanto, observa-se que a área destinada à agricultura sofreu significativa redução, cedendo espaço para a pecuária bovina, atividade essa que concentra em sua produção maior parte das terras produtivas do município, concentradas em sua maioria entre grandes e médias propriedades. $O$ presente trabalho teve como objetivo analisar e apontar os problemas enfrentados no setor agropecuário do referido município, dando importante contribuição para o melhor entendimento da situação socioeconomica no meio rural, como também, o enriquecimento prático e teórico em nível pessoal e acadêmico nesta área.

Considera-se, portanto, que o setor agropecuário no município em estudo, está em estágio bastante atrasado, principalmente a atividade agrícola, se comparado a realizada em outras regiões do país, necessitando assim, de uma profunda reformulação orientada e com maiores investimentos públicos, "reforma agrária" e uma integração com os mercados consumidores e com utilização de tecnologia na produção que proporcione uma maior produção e possa gerar empregos no campo.

\section{Referência}

ANDRADE, Manuel Correia de. A terra e o homem do nordeste: Contribuição ao estudo da questão agrária do nordeste. 6 ed. Recife: Ed Universidade da UFPE, 1998.

AMADOR, Maria Betânia Moreira. A visão sistêmica e sua contribuição ao espaço pecuário de Venturosa e Pedra no Agreste de Pernambuco, 2008. 316f. Tese (Doutorado em Geografia) - Centro de Filosofia e Ciências Humanas. Universidade Federal de Pernambuco, Recife. 
BASE DE DADOS DO ESTADO, BDE. Vacas ordenhadas e produção leiteira. Disponível em: http://www.bde.pe.gov.br/visuálização Acesso em: 15 ago. 2009

CARNEIRO, Maria José. Política Pública e Agricultura Familiar: Uma leitura do PRONAF. Estudo Sociedade e Agricultura. 08 abril 1997. Disponível em: http://bibliotecavirtual.clacso.org.ar/ar/libros/brasil/cpda/estudos/oito/carneiro8.htm Acesso em: 04 out. 2009.

INSTITUTO BRASILEIRO DE GEOGRAFIA E ESTATÍSTICA. Disponível em: http://www.sidra.ibge.gov.br Acesso em: 02 fev. 2006.

LINS, Raquel Caldas. (coord). As áreas de exceção de Pernambuco. Recife, SUDENI/PSU/SER, 1889.

MELO, Mário Lacerda de. Regionalização Agrária do Nordeste. Recífe, SUDENE, CPR. DIV. POL. ESP., 1978.

MELO, Mário Lacerda de. Os agrestes - estudos dos espaços nordestinos do sistema gado-policultura de uso de recursos. Recife, SUDENE Coord. Planej. Regional, 1980.

Monteiro, A. A. et al. Semina: Ciências Agrárias, Londrina, v. 28, n. 4, p. 665-674, out./dez. 2007. Características da produção leiteira da região do agreste do estado de Pernambuco. Disponível em: http://www.uel.br/revistas/uel/index.php/semagrarias/.../2459 Acesso em: 22 out. 2009.

PEREIRA, José Mauricio, SOUZA, Marcio Miceli. Estagnação da Pecuária Bovina no Agreste de Pernambuco. Universidade Católica de Pernambuco, Recife - PE - Caribe. http://www.sober.org.br/palestra/5/601.pdf Acesso em: 03 abril 2009.

SILVA, Airton Marques da e Moura, Epitácio Macário. Metodologia do Trabalho Cientifica. Fortaleza, 2000. p 206.

TINOCO, S.T.S. Conceituação de Agricultura Familiar: Uma Revisão Bibliográfica-2008. Artigo em Hypertexto. Disponível em: < http://www.wfobibos.com/Artigos/2008.4/ AGRIFAMILIAR/ INDEX.HTM.ACESSO EM: 05/10/2009. 